\title{
Work-From-Home Engagement during COVID-19: Implications for Human Resource Management
}

\author{
Olawunmi Eniola ${ }^{1}$ \\ ${ }^{1}$ University of Regina, Saskatchewan, Canada \\ Correspondence: Olawunmi Eniola, University of Regina, Saskatchewan, Canada. Tel: 1-306-541-4604. E-mail: \\ oeeniola2025@gmail.com \\ Received: January 17, 2022 \\ Accepted: February 14, 2022 \\ Online Published: February 23, 2022 \\ doi:10.5539/ijbm.v17n3p134 \\ URL: https://doi.org/10.5539/ijbm.v17n3p134
}

\begin{abstract}
Work-from-home has gained swift and massive adoption due to technological advancement and the large-scale disruption evoked by the COVID-19 pandemic. Work-from-home, also called telecommuting, involves performing work/business responsibilities from a non-office location or typically from home. The work-from-home format has garnered acceptance as the alternative to traditional office work, but it is not without disadvantages. Thus, a thorough insight into the mechanism of the work-from-home format and how it relates to engagement is necessary for organizational leaders and human resource practitioners to cultivate engagement of remote workers. This article illustrates the current state of scholarly research on work-from-home engagement by using the lens of an integrated literature review. This article explains the forces accompanying the work-from-home format and their interactions with employee engagement. The article proposes a conceptual framework of the work-from-home engagement field. The constructs of the work-from-home engagement field, which are the work-from-home positive forces, negative forces, and positive-negative forces, are explained, and the critical implications for human resource management are highlighted.
\end{abstract}

Keywords: Covid-19, employee engagement, recovery, stress, work-from-home

\section{Introduction}

\subsection{The Problem}

The severe global health crisis has triggered an economic downturn and impacted social life due to government measures such as social distancing rules, stay-at-home orders, business lockdowns, and curfews. The COVID-19 pandemic has produced critical disturbances in workplaces globally. The problems imposed by the COVID-19 pandemic prompted new ways of working. Many organizations have adopted the Work-From-Home (WFH) format in dealing with the unprecedented situation. According to International Labour Organization (ILO) assessments, in early January 2021, 93 percent of the world's workers live in countries with workplace closure measures. As of January 2021, the number of employees residing in countries with COVID-19-related workplace closure is persistently high compared to the 85 percent peak reached in late July 2020 (International Labour Organization [ILO], 2021).

Robinson (2020) reported that $38 \%$ of remote employees feel exhausted after daily virtual meetings, while $30 \%$ of remote workers feel stressed. HR Research Institute revealed that COVID-19 dealt a hard blow on employee engagement because many organizations reported low levels of engagement. In a study by HR Research Institute, $31 \%$ of the respondents testified that engagement slumped in the last two years. Specifically, $7 \%$ of the respondents reported that engagement plunged by more than $10 \%$ because many employees retreated to their homes and businesses shut down (Kalvin, 2021).

\subsection{Importance of the Problem}

Research has provided empirical evidence that a high level of engagement boosts organizational outcomes (Harter, Schmidt, \& Hayes, 2002). In a recent survey by HR Research Institute, $72 \%$ to $76 \%$ of the respondents think that engagement positively impacts customer service, wellbeing, company brand, retention, and productivity (Kalvin, 2021). However, in the last two years, the boundaries of work and the workplace have been redefined, which has implications for employee experience, i.e., employee engagement. For instance, the United States Census Bureau indicated that the COVID-19 pandemic had pushed the fast-forward button on the 
work-from-home trend. The number of employees working partially or fully remotely has increased. In essence, the global COVID-19 phenomenon has impacted the daily subjective experience of work, roles, and family lives. It has presented new challenges and consequences. The shift to the work-from-home format caused a boundary loss between work and home. Employees new to remote work struggle to maintain a healthy boundary between professional and personal lives (Giurge \& Bohns, 2020). COVID-19 has caused a vast disruption of lives, work, and the workplace. COVID-19 lockdowns and social distancing rules resulted in the massive adoption of remote work. Therefore, this study investigates what is known about the impact of the work-from-home format on employee engagement.

\subsection{Relevant Scholarship}

Researchers have explored assumptions connected to the work environment because the COVID-19 crisis recontextualized our typical work environment. Specifically, the COVID-19 pandemic is stressful and significantly affects employees ( $\mathrm{Liu}, \mathrm{Chen}, \& \mathrm{Li}, 2021)$. This claim is concurrent with the idea that stressful events drive emotional exhaustion, leading to disengagement from work (Eatough, Chang, Miloslavic, \& Johnson, 2011). The COVID-19 pandemic has posed numerous challenges and negative consequences to employees' work lives (Restubog, Ocampo, \& Wang, 2020). For instance, Patil and Rana (2021) surveyed employees currently working from home in Mumbai, India, to understand their levels of engagement during the COVID-19 crisis. Patil and Rana (2021) found that $62 \%$ of the respondents were more engaged than before COVID-19, 16\% were less engaged than pre-COVID-19, and 22\% reported the same level of engagement. In addition, $59 \%$ of the employees preferred the work-from-home format over the work from office (WFO) model. While Routley (2020) stated that $98 \%$ of people surveyed by the world economic forum prefer to work remotely for the rest of their careers, while $86 \%$ of parents favor remote work compared to $46 \%$ pre-COVID- 19 .

\subsection{Theoretical Framework for the Work-from-Home Engagement Forces}

Kahn (1990) defined engagement as the physical, cognitive, and emotional harnessing of organizational members into their work roles, while disengagement is the uncoupling or withdrawal of selves from work roles. Kahn (1990) further specified that engagement is dependent on conditions or experience, and individual, interpersonal, and organizational factors influence the experience. In the COVID-19 context, environmental factors are included in the factors influencing employees' experience because individuals' behavior is a product of their current environment and individual perception of the environment (Burnes \& Cooke, 2013).

Moreover, Kurt Lewin's field theory indicated that behaviors arise according to the patterns of dynamic interrelationships between individuals and the psychological, social, and physical situation in which they exist. The dynamic interactions are perceived as 'forces' with positive or negative valences (power) (American Psychological Association [APA], 2022). Employee engagement occurs based on the interaction between the employees and the work-home environment within the prevailing COVID-19 crisis. Thus, the dynamic interactions exiting within the work-from-home format can be perceived as forces with positive or negative valences. In addition, Shepherd and Suddaby (2016) suggested that a way of identifying a construct is to borrow constructs from a related discipline. Thus, 'forces' in physics signify influences that cause changes in a situation or object. Similarly, in the COVID-19 work-from-home context, there are forces influencing employees working from home that result in either harnessing or uncoupling of selves from work roles, i.e., work-from-home engagement forces.

Forces exist because of interactions, and individuals experience events stemming from activities and interactions of forces of nature (Fuchs, Corni, \& Pahl, 2021). The interactions between the employees and the work-home environment under the COVID-19 crisis produce forces; in the era of COVID-19, transformations or changes in the employees' state or behavior result from activities and interaction of forces in the work-from-home format. Forces are responsible for many phenomena globally, including biological, chemical, and social experiences (Kalmus, 1993). Individuals experience, i.e., perceive, act upon and react to dynamic processes. Employees respond to environmental stressors, e.g., COVID-19 and the processes in the work-home environment. In the work-from-home format, forces are accountable for harnessing or uncoupling to work roles.

The events in a chemical process can be either bond breaking or forming (Ceron, Echegaray, GutieRrez-Oliva, Herrera, \& Toro-Labbe, 2011). In addition, Kurt Lewin's field theory indicated that an entity that attracts the individual has a positive valence, while an entity that repels has a negative valence (American Psychological Association [APA], 2022). Thus, the work-from-home engagement forces are coupling or uncoupling agents that connect or inhibit engagement (break or form engagement). The work-from-home engagement forces may have a positive or negative valence, i.e., attract or repel engagement.

Furthermore, this study applies the transactional model of stress and coping by Lazarus and Folkman (1984) in 
analyzing the literature about employee engagement and the work-from-home format during the global COVID-19 pandemic. According to Ben-Zur (2020), the transactional model of stress and coping portrays that the relationship between stressors and the outcomes (e.g., physiological and emotional reactions) is mediated by the processes of stress appraisals and the use of coping strategies. However, these mediators (stress appraisals and coping strategies) are impacted by personal variables (e.g., beliefs, self-esteem, social support, economic status, and motivation) and environmental variables (e.g., demands, constraints). In addition, stress appraisal involves assessing the stressor's relevance, meaning, threat, loss, or challenge (primary appraisal) and evaluating resources and coping capability about changing the stressful situation (secondary appraisal). While coping is restricted to the context in which the event occurs, it entails changing cognitive and behavioral efforts to manage the external or internal demands identified as challenging the person's resources.

In the context of COVID-19 work-from-home, the stressor, COVID-19, and the outcome, i.e., work-from-home engagement, is mediated by stress appraisals and coping strategies, which can be classified as either positive or negative. Specifically, stress may be appraised positively or negatively, and employees may select positive or negative coping strategies. The stress appraisal mechanism's selection and coping strategies' adoption depend on personal and environmental factors. On the one hand, when employees feel autonomous, competent, and connected with their social environment during a crisis, they are more prone to assess the crisis as challenges that can be controlled and overcome rather than threats or damages that may undermine their wellbeing. Therefore, such employees demonstrate confidence in personal control over stressful situations and are motivated to adopt control coping instead of escape coping. On the other hand, if the employees are deficient in the essential psychological resources (autonomy, competence, and social connections), the employees may experience a lack of control, helplessness, and alienation. They may select escape coping to withdraw from the problem and regulate emotional distress (Tao, Lee, Sun, $\mathrm{Li}, \& \mathrm{He}, 2021$ ).

Based on this premise, this study organized the work-from-home engagement forces that manifest during the COVID-19 pandemic into three categories. The first category is the positive work-from-home forces that do not undermine employee wellbeing and connect/attract engagement. According to the control theory, monitoring and controlling of behaviors occur in systems to generate the desired outcome (American Psychological Association [APA], 2022). Similarly, the field theory stated that forces in a field constantly interact with each other and are subject to change (Burnes \& Cooke, 2013). Thus, the second category is the negative work-from-home forces that may be perceived as threats or damages and which disconnect/inhibit or repel engagement and therefore require control or change. Still, the continuum approach indicates that "behavior ranges over a continuum from effective functioning to severe abnormality" (American Psychological Association [APA], 2022). Some work-from-home forces could tilt from time to time toward the opposite end of the continuum, i.e., positive to negative. Thus, the third category is the work-from-home forces that could deviate from positive to negative or vice versa because excess or lack of them may be detrimental to wellbeing and therefore require control/change. In addition, some of the forces that fall within the positive to negative continuum are more prone to varying individual appraisal/perceptions of their impact on wellbeing. Burnes and Cooke (2013) indicated that an individual's behavior is dependent on both impinging forces and the subjective perception or interpretation of these forces.

\section{Method}

This study synthesized the existing knowledge on the phenomena of work-from-home and engagement. The guidelines stipulated by Torraco $(2005 \& 2016)$ formed the basis for synthesizing the literature about the concept of the work-from-home and employee engagement during the ongoing COVID-19 pandemic. The databases search included Web of Science, ABI/Inform, Jstor, Proquest, NexisUni, and Education database. The database search generated publications based on the following keywords: work engagement and COVID-19, COVID-19 and work-from-home, employee engagement and COVID-19, COVID-19 and the workplace, work-from-home and engagement, remote work and engagement, teleworking, and engagement. The abstracts from these publications were screened for any of the keywords mentioned above. Some publications were excluded from this study. The inclusion criteria for this study are based on the work-from-home format or remote work, COVID-19, and engagement. A total of 58 publications were included in the analysis. The analyzed publications include 25 articles that addressed working from home and engagement. Specifically, articles that indicated that the sampled participants were exclusively working from home or cited that a high percentage of the sample was working from home. The remaining publications addressed COVID-19 issues, engagement, or just remote work and relevant theories. The review resulted in a conceptual model that outlined several key constructs around the work-from-home and engagement concept. The model of the work-from-home engagement field was created by grouping forces acting on employee engagement according to their impacts using the Microsoft Office program. 


\section{Results}

\subsection{Work-from-Home Positive Forces (+)}

Employees working from home and those participating in the hybrid work format had higher levels of work engagement than those who worked at the office, based on a study involving 709 participants in China (Song, Wang, Li, Yang, \& Li, 2020). In a survey conducted by the World Economic Forum (Routley, 2020), the top benefits of remote work indicated by employees include a flexible schedule, the ability to work from any location, and no commuting. Anguelov and Angelova (2021) found that 158 employees in the ICT companies in Bulgaria had a positive attitude toward the home office during the COVID-19 pandemic. The employees considered working at home more appealing than traditional office work because of less control and opportunity for making personal work plans, which affects employee motivation and engagement.

Mehta (2021) established that employees working remotely experience autonomy in their work, and perception of autonomy has a significant impact on work engagement based on a study of 440 IT employees in India. In addition, Mehta (2021) found that work-from-home convenience has a significant positive relationship with the work engagement of work-from-home employees. The convenience of working from home is due to the absence of commute time, lower frequency of work breaks, and fewer sick days.

Self-leadership is a cognitive and behavioral strategy for setting, self-influencing, regulating, and controlling one's own goals and monitoring their fulfillment, which may contribute to efficient remote work (Galanti, Guidetti, Mazzei, Zappala, \& Toscano, 2021). Based on a study of 209 Italian employees working remotely, from which $91.9 \%$ have not performed their duties from home before COVID-19, Galanti et al. (2021) found that self-leadership is positively related to work engagement $(\beta=0.23 ; \mathrm{P}<0.01)$.

Telework effectively supports employee wellbeing and engagement, according to a study of 260 Italian workers that are grouped into high-to low-quality teleworkers and zero teleworkers (Miglioretti, Gragnano, Margheritti, \& Picco, 2021). These findings are due to the teleworking conditions whereby the high teleworkers had better quality workstations, higher autonomy, and virtual leadership. Miglioretti et al. (2021) confirmed that high-quality telecommuters reported lower job demands than low-quality telecommuters and zero teleworkers. In addition, high-quality telecommuters experienced higher work engagement than low-quality telecommuters and zero teleworkers.

A comparative analysis of the UWES conceptualization of engagement, vigor, dedication, and absorption of 211 management-level hotel employees in Turkey during the COVID-19 pandemic yields a higher level of vigor for 105 management-level employees working from home versus 106 management-level employees working at the workplace (Chi, Saldamli, \& Gursoy, 2021). However, there is no difference in dedication $(\mathrm{t}=-0.60, \mathrm{p}=.55)$ and absorption $(\mathrm{t}=-1.18, \mathrm{p}=.24)$ across the groups of management-level employees working from home and at the workplaces. Thus, Chi et al. (2021) validated that working-from-home influences engagement via promoting vigor but not dedication and absorption.

Palumbo (2020) established that the adverse effects of working from home on work-life balance were mediated by work engagement. Telecommuting from home positively enhances remote workers' absorption, dedication, vigor, and overall work engagement. Work engagement decreases the remote employees' perception of work-related fatigue and aids their ability to recover. Work engagement minimizes the perceptions of work-life imbalance.

In a study of 400 Romanian teachers working online during the pandemic, Obrad (2020) confirmed that received support has a positive relationship with job engagement $(\beta=0.16, \mathrm{p}<0.05)$. Received support is positively related to resilience $(\beta=0.27, p<0.001)$. The help and understanding the teachers received from the department or school/university management contributed significantly to building their resilience. Moreover, based on a study of 610 academic employees from three Norwegian universities after implementing COVID-19 restrictions, perceived usefulness and perceived ease of use of technology tools had positive associations with technology acceptance, and technology acceptance also had a positive connection $(\beta=0.19, \mathrm{p}<0.001)$ with work engagement (Shamsi, Iakovleva, Olsen, \& Bagozzi, 2021). In addition, Shamsi et al. (2021) confirmed that technology acceptance has a significant and positive indirect effect from perceived team support to work engagement.

HRM practices that include digital engagement and increased communication reduced employees' fear and anxiety, leading to motivated and engaged employees in 26 Sri Lankan companies during the battles with COVID-19 (Adikaram, Naotunna, \& Priyankara, 2021). According to Adikaram et al. (2021), the digital engagement for employees working remotely includes online games, quizzes, singing and talent competitions, 
art competitions for employees' kids, zoom chats, exchange of pictures of hobbies such as cooking, gardening, playing musical instruments via social media, virtual coffee sessions, and celebrations of birthdays and religious events. Increased communication involves online meetings, emails, one-to-one discussions, constant SMS texting, positive messages and motivational videos via social media, and direct contacts by line managers, HR, and team leaders.

Similarly, Patil and Rana (2021) suggested that inclusion, autonomy, communication, learning and development, flexibility, rewards, and leveraging virtual learning (webinars, virtual coaching, and virtual training) are important drivers of job engagement during COVID-19.

\subsection{Work-from-Home Negative Forces (-)}

During the COVID-19 lockdown in the UK, employees working from home experienced work intensification and online presenteeism due to the sudden transition to the online format of working (Adisa, Ogbonnaya, \& Adekoya, 2021). Work intensification and online presenteeism further generated stress that threatened the workers' social and personal resources and caused psychological strain and low levels of work engagement. The work at home necessitated that employees take on more tasks regardless of family-related duties such as childcare and chores, resulting in increased time pressure. In addition, Adisa et al. (2021) confirmed that the work-from-home employees spent lengthy periods of time on digital platforms because of virtual meetings, constant pressure to check and respond to work-related emails outside of working hours, and the need to prove that they are actually working and not neglecting their duties.

Palumbo (2020) used secondary data collected from 9,877 respondents during the sixth European Working Conditions Survey (EWCS) to provide insights into the current issues of working from home under the COVID-19 pandemic. Palumbo (2020) established that home-based telecommuting negatively impacted the work-life balance of public servants. The heightened work-related fatigue provoked by remote work may generate physical and emotional exhaustion.

Obrad (2020) revealed a complex relationship between stress, resilience, and work engagement in a study of 400 Romanian teachers working online during the pandemic. Obrad (2020) found that job constraints and stress have adverse effects on job engagement $(\beta=-0.42, \mathrm{P}<0.001)$ of the teachers. The teachers' stressors were from new technologies, new tools involved in online teaching, and time requirement for transposing and adapting teaching materials for online delivery during COVID-19. The intensity of the stress affected the coping mechanism, i.e., the resilience of the teachers. Thus, stress is negatively connected to resilience $(\beta=-0.17, p<0.05)$.

Based on a four-wave study of 965 employees before the COVID-19 and during the COVID-19 pandemic in Finland, "work engagement decreased during autumn 2020 when psychological distress had a stronger negative association with work engagement compared to that before the COVID-19 outbreak" (Oksa, Kaakinen, Savela, Hakanen, \& Oksanen, 2021, p. 6). According to the World Economic Forum (Routley, 2020), the most significant battle with remote work is the blurred lines between work and personal life. Employees cited that unplugging from work is difficult because there is no clear-cut change in location and defined office hours. In addition, loneliness and the lack of person-to-person communication pose challenges for employees. Some employees assumed that their managers would not recognize their total professional contribution because they lacked in-office contact.

In a study of 22 middle-level employees of Indian companies and MNCs in India, Varshney (2021) found that working from home raises mental health and engagement issues because of more work hours and overlapping hours of professional and personal duties. Thus, working from home produces instability and imbalance in professional and personal activities. In addition, motivational and engagement techniques are required to sustain the home-bound employee's productivity because the psychological states of WFH employees are affected by (I) alienation (social isolation), COVID-19 mortality, and obsessive-compulsive disorder (OCD), (II) organizational conditions such as trust, communication, and pay issues and (III) lockdown life which causes social isolation and work-life balance problem due to chores and children.

According to Galanti et al. (2021), COVID-19 lockdown led to the shift to the work-from-home format, which caused social isolation, work-family conflict, and distracting work environment. Galanti et al. (2021) stated that these job demands pose negative work stress. Galanti et al. (2021) confirmed that social isolation ( $\beta-0.36$; $\mathrm{P}<0.01$ ) is negatively related to work engagement based on a sample of 209 employees with children working from home. Hence, the author identified social isolation as one of the significant downsides of remote work.

During a study of 211 management-level hotel employees, out of which 105 were working from home, Chi et al. (2021) found that the higher the absorption, the higher the burnout, and the absorption for all employees is 
positively related to burnout. Specifically, the impact of absorption on burnout is more significant for managers who work from home. The positive effect of absorption on burnout is significantly higher for the WFH group, i.e., too much engagement (e.g., high absorption) triggers burnout. So, Chi et al. (2021) established that working status (work-from-home or working in the workplace) moderated the relationship between absorption and burnout.

Based on a study of 885 employees in 177 Slovenian organizations, occupational stress has a higher negative effect on work engagement during the COVID-19 pandemic $(\beta=-0.602, p<0.01)$ compared to $(\beta=-0.443, p<$ 0.01) pre-COVID-19 (Rožman, Peša, Rajko, \& Štrukelj, 2021). The difference in the results is because employees face higher stress in performing work tasks, emotional exhaustion, depression, tension, panic, and problems with concentration due to COVID-19. In addition, job satisfaction has a lesser positive effect on work engagement during COVID-19 ( $\beta=0.412, \mathrm{p}<0.01)$ than pre-COVID-19 $(\beta=0.695, \mathrm{p}<0.01)$. In general, employees perceived work engagement lower during the COVID-19 pandemic than before. Thus, Rožman et al. (2021) confirmed that building a supportive work environment with reduced occupational stress is crucial in increasing work engagement during the COVID-19 pandemic work-from-home.

In a study of 258 respondents working from home in different Indian organizations, psychological contract breach is negatively related to work engagement: unmet expectations negatively affected employees during the COVID-19 pandemic (Karani, Deshpande, Mall, \& Jayswal, 2021). Work engagement is an indicator of psychological wellbeing. According to Karani et al. (2021), psychological contract breach also leads to job stress because of the unmet expectations and work-from-home environment, while job stress further impacts work engagement.

Mikołajczyk (2021) confirmed from a study of 19 HR Managers in Poland that the psychological states of the employees due to COVID-19 impacted the subjects of developmental forms. Thus, their organizations delivered the most frequently requested training based on the psychological conditions of the employees. The training includes remote work and communication in dispersed teams, time management, emotions and stress management, attentiveness training, empathic communication and assertiveness, healthy lifestyle, work-life balance, and mental health programs. In addition, Mikołajczyk (2021) reported a decline in employee engagement and heightened fatigue due to multiple online development initiatives.

Based on a study of 220 managers in Thailand, Vietnam, Indonesia, and Taiwan, Chen and Sriphon (2021) revealed that remote work interrupted the trust and social exchange relationships between employees and managers during the pandemic. The deteriorating relationship is because managers implemented more controls and monitoring of employees working remotely. Consequently, COVID-19 work-from-home reduced leadership quality in organizations, thus affecting employee engagement.

From an in-depth interview of 19 HR Managers in Poland, Mikołajczyk (2021) found that the COVID-19 pandemic caused changes to employee development programs which subsequently impacted employee engagement. During the pandemic, many organizations in Poland changed the form and methodology of employee training. These changes in employee development programs are due to budgetary constraints, remote work, and the psychological states of the employees. For instance, online training was compacted into short versions, and more webinars were offered. Specifically, the webinar does not support focus and engagement.

\subsection{Work-from-Home Positive-Negative Forces (+-)}

Working from home could produce paradoxical outcomes (De Klerk, Joubert, \& Mosca, 2021). On the one hand, it may lead to higher employee engagement, and on the other hand, it could exacerbate negative experience that reduces engagement. Based on a study of 25 employees working from home during the COVID-19 in South Africa, De Klerk et al. (2021) established that working remotely poses both flexibility and pressures. Ironically, WFH may contravene family roles and increase work-family conflict because working from home distort work and home boundaries and cause difficulties in prioritizing and achieving work-life balance. At the same time, employees working remotely are probably satisfied and less prone to experience work-family conflict because working from home support the experience of increased personal and contextual resources.

Chi et al. (2021) demonstrated that working-from-home results in both positive and negative employee behavioral outcomes. On the one hand, employees who can regularly detach from work are more likely to experience less job stress and achieve job benefits which cause positive behavioral intentions (e.g., low turnover intentions). On the other hand, a lack of detachment may increase the psychological effects of adverse job conditions (e.g., burnout), consequently producing undesirable behavioral outcomes (e.g., high turnover intentions). However, in the COVID-19 work-from-home context, neither physical nor psychological detachment is likely effective because of the unclear line between work and home, which extends work stress and 
undermines detachment from work.

Diversity-oriented leadership behaviors shape transparent internal communication practices that foster employees' intrinsic needs satisfaction during the COVID-19 crisis (Lee, Tao, Queenie, \& Sun, 2021). This finding is based on a study of 490 full-time employees in 20 industries in the United States, out of which $73.3 \%$ work in companies with work-from-home options. Specifically, Lee et al. (2021) confirmed that transparent internal communication and intrinsic needs satisfaction impact job engagement. Intrinsic needs satisfaction positively mediates the relationship between diversity-oriented leadership and job engagement, while transparent internal communication negatively mediates the relationship between diversity-oriented leadership and job engagement. Job engagement positively mediates the relationship between intrinsic needs satisfaction and knowledge sharing. Thus, leadership style accounts for higher levels of job engagement and knowledge sharing among employees even under an unstable organizational environment. Still, there is evidence to argue that human needs are insatiable because of unforeseen contingencies in the natural world (Gargnier, 1993). Leadership quality has degenerated due to excessive monitoring of remote workers (Chen \& Sriphon, 2021).

In a study of 158 employees in the ICT companies in Bulgaria, Anguelov and Angelova (2021) confirmed that working from the home office does not affect the employees' motivation and engagement in achieving the company's goals. The reason is that the home office has no effect on the employees' creativity and causes neutral to a negative impact on teamwork due to indirect communication and difficulties in coordination, planning, and decision making. On the contrary, Shamsi et al. (2021) confirmed from a study of 610 academic employees from three Norwegian universities that perceived team support $(\beta=0.30, p<0.001)$ is positively related to work engagement. Team support plays an extrinsic motivational role by helping employees devote efforts and abilities to perform tasks. Moreover, Miglioretti et al. (2021) revealed that job resources, e.g., supervisor support and co-worker support were significantly higher among high-quality teleworkers than low-quality teleworkers and zero teleworkers. In this study, teleworkers are categorized as high- and low-quality teleworkers based on the extent of an agile workplace, i.e., quality of workstation settings, the worker's flexibility, i.e., substantial autonomy, and virtual leadership, i.e., clarity of assigned work objectives.

Albro and McElfresh (2021) found that the job engagement scores of 21 faculty librarians working from home during the COVID-19 pandemic at Clemson University significantly decreased between the six-week and six-month checkpoints. The reduction in the job engagement of the librarians between the start of the COVID-19 work-from-home and at the 6-month marker is attributed to the employee-organization relationship, which caused poor information flow. The librarians experienced information flow differently due to the rank, tenure, and length of employment. Thus, the workplace experiences, i.e., engagement, are impacted because of the differences in information flow.

Tao et al. (2021) stated that in times of COVID-19 crisis, employees' satisfaction of the three fundamental psychological needs: autonomy, relatedness, and competence are related to coping and escape mechanisms while the coping mechanism is associated with organizational engagement. Concurrently, scholars have found that motivational and personality characteristics do not produce a one-size-fits-all outcome for work-from-home engagement. It all depends on the depth and type of personality factors and motivational needs. For instance, job outcomes (work engagement and job satisfaction) and telecommuting preference are related to person-centered motivational and personality characteristics based on a study of 199 employees during the COVID-19 pandemic (Bakaç, Zyberaj, \& Barela, 2021). In this study, Bakaç et al. (2021) grouped the participants into three categories according to their motivational and personality scores. Profile 1: high conscientiousness and autonomy and medium-high extraversion and self-regulation. Profile 2: medium-high conscientiousness and autonomy, low extraversion, and medium-low self-regulation. Profile 3: medium-low self-regulation, conscientiousness, autonomy, and extraversion. They found that individuals in profile $2 \& 3$ reported higher telecommuting preferences than profile 1 , while profile 1 reported high work engagement, job satisfaction, and perceived productivity, compared to other profiles. In addition, for the individuals in profiles $2 \& 3$, work engagement significantly mediates the relationships between motivational cum personality factors and job satisfaction and perceived productivity than for employees in profile 1 .

Similarly, the satisfaction of basic human needs is linked to enhancing motivation and wellbeing in a study of 199 German employees (Schade, Digutsch, Kleinsorge, \& Fan, 2021). Schade et al. (2021) established that the work-related basic need of relatedness was significantly lower when working from home than in the office. However, there was no statistically significant difference in autonomy and competence needs when working from home or in the office. Thus, relatedness to colleagues is the work-related need most impacted by working from home. Higher competence needs satisfaction accounted for higher daily work engagement, flow, and affect. In addition, organizational and personal resources such as role clarity, emotional exhaustion, segmentation 
preference, and childcare duties did not influence any need's fulfillment working from home in the sampled employees.

Shamsi et al. (2021) confirmed from a study of 610 academic employees from three Norwegian universities that mental load $(\beta=0.17, p<0.001)$ is positively related to work engagement. In this case, the mental load is constructed as a practical challenge or positive/cognitive job demands during remote working. Mental load results in higher work engagement because challenging stressors are positively associated with employees' motivation and wellbeing. However, it can be argued that an excessive mental load may prevent psychological detachment and lead to burnout (Chi et al., 2021). At the same time, Shamsi et al. (2021) established that mental load was negatively related to technology acceptance. Technology acceptance has a significant and negative indirect relationship between mental load and work engagement.

An investigation of the change in sleeping hours, interactions with supervisors, and working hours of 3776 employees who worked from home compared to 11,894 employees who did not work from home in Japan indicated some similarities for both groups (Amano, Fukuda, Shibuya, Ozaki, \& Tabuchi, 2021). The close communication with supervisors and colleagues, working hours of $<40 \mathrm{~h} / \mathrm{week}$, and the absence of a mental disorder was associated with high work engagement in employees who worked from home and those who did not. However, Amano et al. (2021) found factors such as unchanged opportunities for physical activity, unchanged and decreased sleeping hours, unchanged opportunities for eating breakfast, and working hours of greater than or equal to $40 \mathrm{~h} /$ week are independently associated with lower engagement for employees who worked from home. For example, the proportion of WFH employees who had increased their sleep duration had higher work engagement than those who experienced decreased sleep duration.

A comparison of the outcomes of the mindfulness-based intervention (Mindfulness In Motion) for healthcare professionals of the Ohio State University Wexner Medical Center did not yield any significant difference in the work engagement scores of the 124 pre-COVID-19 participants compared to the 99 COVID-19 participants who received virtual delivery (Klatt, Bawa, Gabram, Westrick, \& Blake, 2021). Klatt et al. (2021) established similar improvements in work engagement but significant differences in emotional exhaustion and perceived stress for pre-COVID cohorts compared to COVID cohorts.

Lastly, in a study of 209 Italian employees with children, Galanti et al. (2021) established a positive and significant relationship $(\beta=0.19 ; \mathrm{P}<0.01)$ between the fear of COVID-19 and remote work engagement. There are many possibilities for a counter-argument. Moyo (2020) established that the perceived risk of the COVID-19 pandemic due to the unabating transmission of the coronavirus led to disengagement in 177 working adults in Zimbabwe. Similarly, COVID-19-mortality salience has a negative effect on job engagement via anxiety based on two studies from China and the United States. The negative relationship between anxiety and job engagement became positive only when servant leadership was higher (Hu, He, \& Zhou, 2020).

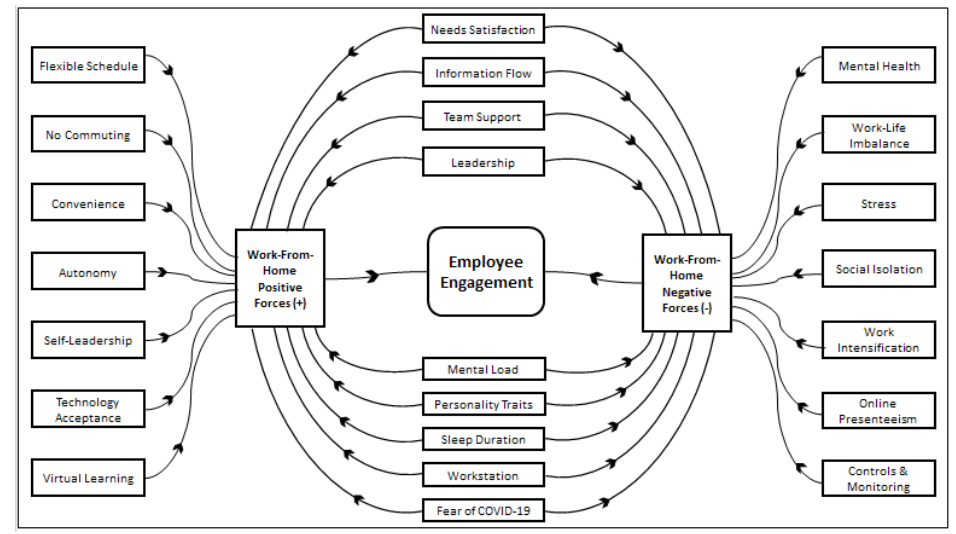

Figure 1. Work-From-Home engagement field

\section{Discussion}

\subsection{Theoretical Implications}

COVID-19 brought a new reality to the world of work and has presented a new way of thinking about work-from-home engagement. Shepherd and Suddaby (2017) indicated that the popular strategy in naming a construct is to borrow constructs from a related discipline or use common words that closely portray the 
phenomenon of interest. Thus, this article proposes that the work-from-home format under the COVID-19 crisis is synonymous with a field. In the scholarly realm, a field is where a subject of scientific investigation or artistic representation can be observed in its location or context. Thus, the home where employees conduct their work activities is a field, and employee engagement is being observed from home under the COVID-19 context. In physics, a field is a region where a particular condition prevails, especially where a force or influence is active. There are prevailing conditions and forces acting on employee engagement in the work-from-home format. Similarly, the Bourdieusian framework indicates that a field is a social space consisting of a network of relations between agents in a more extensive network of power (Schmaus \& Wimmer, 2013). The employees' home is a social space where business activities are conducted within a network of relations with family, supervisor, colleagues, and clients and are enveloped by the enormous COVID-19 pandemic.

Thus, the article utilized the term 'work-from-home engagement field' to capture the prevailing conditions or active forces and influences under the work-from-home format. The interactions between employees, COVID-19, and the work-from-home exert forces in the engagement field. Shepherd and Suddaby (2017) stated that ideas emerge from interweaving existing knowledge or extant literature and emerging knowledge. The constructs in the work-from-home engagement field are summarized from empirical findings from extant literature about engagement and work-from-home under the COVID-19 crisis. In addition, researchers indicated that statements of relationships are constructed about units or constructs observed or appraised in the observed world (Bacharach, 1989). Thus, it is proposed that the work-from-home exerts forces on employee engagement. The forces can be either repelling or attracting and may sometimes produce neutral effects or mixed effects depending on the uniqueness of the circumstances or context. The work-from-home forces can swing in both directions (positive and negative), and efforts can be made to control the direction of the work-from-home forces. Efforts are required to establish a balance or adjust the conditions surrounding work-from-home engagement to achieve desired outcomes.

Bacharach (1989) stated that a concept might respond to the questions of how, when, and why and denote the relations among concepts. In addition, an idea contains logical variables and has explanatory potential. In line with these assumptions, the work-from-home engagement field explains the relationships among constructs and variables operating when employees work from home under the ongoing COVID-19 crisis. It explains the forces that nurture engagement and identifies the forces that require strengthening or weakening to foster engagement. Firstly, the work-from-home positive and negative forces are both moving in the direction of employee engagement. Both the positive and negative forces act on employee engagement or cause changes in employee engagement, but their impacts are different. The work-from-home forces can either attract engagement, i.e., produce positive effects $(+v e)$, or repel engagement, i.e., produce negative results (-ve). In essence, work-from-home forces wield effects on employee engagement. Working from home may not generate the same effects for everybody depending on how the situation is perceived or interpreted based on the appraisal of stress and the choice of coping mechanism.

Secondly, this study provided empirical evidence from extant literature about the linkages of the constructs intervening with engagement during the work-from-home. There are three constructs in the work-from-home engagement field. The constructs are work-from-home positive forces, work-from-home negative forces, and work-from-home positive-negative forces. The variables of the work-from-home positive forces do not undermine employee wellbeing. They include no commuting, self-leadership, autonomy, convenience, flexible schedule, etc. The variables of the work-from-home negative forces are threats, challenges, or damages and thus require control or change. They include work-life imbalance, mental health, stress, social isolation, online presenteeism, etc. The variables of the work-from-home positive-negative forces are more prone to varying individual perceptions of their impact on wellbeing and require control. An excess or lack of them may be detrimental to wellbeing. They include mental load, personality traits, sleep duration, leadership, needs satisfaction, etc. Hence, the work-from-home positive forces should be strengthened while the work-from-home negative forces should be weakened.

Thirdly, the forces in the work-from-home engagement field are triggered by the switch from traditional office to work-from-home format coupled with the interference from COVID-19. Thus, working from home leads to contradictory outcomes, sometimes positive, negative, or between positive and negative. The positive, negative, and positive-negative forces occur due to a change from the usual workplace to the work-from-home format, an imbalance in the environment due to working from home, a shift in the work routines or status quo, the need to develop new work routines and habits, presence or absence of resilience, poor to excellent coping capacity, and the way of responding to the work-from-home format. Figure one depicts the work-from-home engagement field. The work-from-home engagement field maps out the forces shaping employee engagement. It illuminates how 
the forces interact in the work-home environment. In addition, the work-from-home engagement field can be utilized in examining the actors behind the engagement states of employees working from home.

\subsection{Implications for Human Resource Management}

This study has significant implications for managers because they need to know the forces that interplay when employees are working from home. Individual and organizational contexts are important contingent variables in the circumstances precipitated by COVID-19. The individual and organizational contexts determine the forces that come into play when working from home. Shuck and Wollard (2010) indicated that both individual and organizational approaches are valuable in examining employee engagement because engagement is a personal decision made by the employee. Engagement also depicts the current temperature reading of an organization. For instance, employees' adaptability in the form of self-leadership, planning, personal resources, etc., is essential ingredients in promoting work-from-home engagement. Likewise, pre-COVID-19 studies reported that self-leadership enables higher psychological capital and job embeddedness, influencing work engagement (Harunavamwe, Nel, \& Van Zyl, 2020). Personal resources such as self-efficacy, organizational self-esteem, and optimism are positively related to work engagement (Xanthopoulou, Baker, Demerouti, \& Schaufeli, 2009).

At the same time, organizational leadership, team support, and information flow cannot be overlooked in fostering work-from-home engagement. For instance, leadership has been identified as one of the most important antecedents of employee engagement (Macey \& Schneider, 2008). Team or co-worker support is directly related to remote workers' engagement during the COVID-19 pandemic (Karani \& Mehta, 2021). Bedarkar and Pandita (2014) conceptualized that leadership and communication are key drivers of employee engagement.

Still, good work-from-home practices that support productivity and engagement involve checking and balancing sleep duration, leisure time, physical activities, hours of work, and mental wellbeing. This suggestion is consistent with the idea that a high workload can decrease employee engagement during the COVID-19 crisis (Fabiyani, Sudiro, Moko, \& Soelton, 2021). In addition, mental health problems are negatively associated with work engagement and intrinsic motivation (Kotera, Mayer, \& Vanderheiden, 2021).

Yet work-from-home properties may not be favorable toward employee engagement. For example, social isolation, unconducive workstations, relatedness needs, and specific personality characteristics do not support remote work. In this regard, organizations are charged with providing support for the employees based on their unique situations. One of the ways organizations can support employees working from home is through mastery experiences. According to Sonnetag and Fritz (2007), mastery experiences involve providing off-work challenging experiences and learning opportunities in another domain that distract employees from the job during the off-work time. Mastery experiences challenge an individual without straining their capabilities, and they include but are not limited to language class and learning a new hobby. Thus, learning and development activities should not be focused solely on the job but should include mastery experiences that can help build self-efficacy, resilience, competencies, and other internal resources that could help employees recover from job-related stress. In addition, employee development programs should be needs-driven to be effective, i.e., learning offerings should meet the current and evolving learning needs of those it is intended to serve (Torraco \& Lundgren, 2020). At the same time, the form or methodology of meeting the development needs is also a critical factor. Mikołajczyk (2021) indicated that a responsive HRD that achieves effective employee development entails buffering virtual training through using different learning strategies collaborative and interactive processes. In essence, meeting employees' development needs should go beyond using less interactive methods, e.g., webinars. With the prevalence of digital work and learning, organizations should scrutinize the learning design and ensure online development programs are needs-based, interactive, and engaging. Training must adapt to changing environmental conditions to be effective (Garavan, McCarthy, Lai, Murphy, Sheehan, \& Carbery, 2021).

In a volatile environment like the one provoked by COVID-19, employer-employee support will catalyze work-from-home engagement. According to the HR Research Institute, organizations that prioritize a caring/positive work culture and make engagement a partnership across all job levels and departments perform better in employee engagement (Kalvin, 2021). Such caring work culture could include a flexible work schedule and digital engagement activities. Flexible work arrangements ensure a healthy work-life balance by helping employees manage work and non-work responsibilities (Allen, Johnson, Kiburz, \& Shockley, 2013). Digital engagement activities such as games, challenges, and competitions help employees remain motivated and engaged during the COVID-19 crisis (Chanana \& Sangeeta, 2020).

In essence, the work-from-home engagement field would enable behavioral change by helping employees, and human resource practitioners understand the forces encroaching in the work-from-home format. Specifically, 
changes in employee engagement would occur by making changes to the forces (i.e., strengthening or weakening) in the work-from-home engagement field.

\subsection{Recommendations for Future Research}

This study underscored that recovery from stress is a crucial determinant of work-from-home engagement during COVID-19. Numerous studies cited job constraints, stress, occupational stress, psychological distress, emotional exhaustion, etc., as significant forces impeding the employee engagement of remote workers. There is a need for research on recovery from work-from-home stressors or how employees working from home can recover. Due to the lack of separation between home and work, restoration or return to pre-stressor level may be difficult compared to when employees work in the traditional office. For instance, research has pointed to psychological detachment as a means of balancing work overtime and work-life conflict based on the conventional work format (Skurak, Malinen, Näswall, \& Kuntz, 2021). Psychological detachment has been described by Sonnentag and Fritz (2007) as a process of mentally 'switching off' from work to facilitate recovery. Still, being physically distant from the workplace could be essential for recovery. Thus, how is recovery feasible when there is no boundary between work and home? In addition, COVID-19 is a stressor (Zheng et al., 2020). Stressors make it difficult to detach from work during the off-job time, decrease the experience of control outside work, and deplete self-regulatory resources required for recovery (Sonnentag \& Fritz, 2007). Thus, the recovery from work-from-home strains during COVID-19 calls for further investigations.

\subsection{Limitation of Study}

The study derived the work-from-home engagement field from findings drawn from the extant literature. However, it is essential to conduct more empirical studies further to validate the propositions.

\section{Acknowledgments}

This acknowledgment goes to the University of Regina for providing resources for the research.

\section{References}

Adikaram, A. S., Naotunna, N. P., \& Priyankara, H. P. R. (2021). Battling COVID-19 with human resource management bundling. Employee Relations: The International Journal, 43(6), 1269-1289. https://doi.org/10.1108/ER-08-2020-0390

Adisa, T. A., Ogbonnaya, C., \& Adekoya, O. D. (2021). Remote working and employee engagement: A qualitative study of British workers during the pandemic. Information Technology and People. 1-16. https://doi.org/10.1108/ITP-12-2020-0850

Albro, M., \& McElfresh, J. M. (2021). Job engagement and employee-organization relationship among academic librarians in a modified work environment. The Journal of Academic Librarianship, 47, 1-8. https://doi.org/10.1016/j.acalib.2021.102413

Allen, T. D., Johnson, R. C., Kiburz, K. M., \& Shockley, K. M. (2013). Work-family conflict and flexible work arrangements: Deconstructing flexibility. Personnel Psychology, 66, 345-376. https://doi.org/10.1111/peps.12012

Amano, H., Fukuda, Y., Shibuya, K., Ozaki, A., \& Tabuchi, T. (2021). Factors associated with the work engagement of employees working from home during the COVID-19 pandemic in Japan. International Journal of Environmental Research and Public Health, 18, 1-12. https://doi.org/10.3390/ijerph181910495

American Psychological Association. (n.d). Continuum Approach. In APA dictionary of psychology. Retrieved January 26, 2022, from https://dictionary.apa.org/continuum-approach

American Psychological Association. (n.d). Control Theory. In APA dictionary of psychology. Retrieved January 26, 2022, from https://dictionary.apa.org/control-theory

American Psychological Association. (n.d). Field Theory. In APA dictionary of psychology. Retrieved January 28, 2022, from https://dictionary.apa.org/field-theory

Anguelov, K., \& Angelova, M. (2021). Home office effects on the motivation of ICT companies' employees. Entrepreneurship and Sustainability Issues, 8(4), 10-28. https://doi.org/10.9770/jesi.2021.8.4(1)

Bacharach, S. B. (1989). Organizational theories: Some criteria for evaluation. Academy of Management Review, 14(4), 496-515.

Bakaç, C., Zyberaj, J., \& Barela, J. C. (2021). Predicting employee telecommuting preferences and job outcomes amid COVID-19 pandemic: a latent profile analysis. Current Psychology, 1-16. 
https://doi.org/10.1007/s12144-021-02496-8

Bedarkar, M., \& Pandita, D. (2014). A study on the drivers of employee engagement impacting employee performance. Procedia - Social and Behavioral Sciences, 106-115. https://doi.org/10.1016/j.sbspro.2014.04.174

Ben-Zur, H. (2020). Transactional Model of Stress and Coping. In Zeigler-Hill V., Shackelford T. K. (Eds.), Encyclopedia of Personality and Individual Differences. Springer, Cham. https://doi-org.libproxy.uregina.ca/10.1007/978-3-319-24612-3_2128

Burnes, B., \& Cooke, B. (2013). Kurt Lewin's field theory: A review and re-evaluation. International Journal of Management Reviews, 15, 408-425, https://doi.org/10.1111/j.1468-2370.2012.00348.x

Ceron, M. L., Echegaray, E., GutieRrez-Oliva, S., Herrera, B., \& Toro-Labbe, A. (2011). The reaction electronic flux in chemical reactions. Science China, 54(12), 1982-1988. https://doi.org/10.1007/s11426-011-4447-z

Chanana, N., \& Sangeeta. (2020). Employee engagement practices during COVID-19 lockdown. Journal of Public Affairs, 1-18. https://doi.org/10.1002/pa.2508

Chen, J. K. C., \& Sriphon, T. (2021). Perspective on COVID-19 pandemic factors impacting organizational leadership. Sustainability, 13(3230), 1-21. https://doi.org/10.3390/su13063230

Chi, O. H., Saldamli, A., \& Gursoy, D. (2021). Impact of the COVID-19 pandemic on management-level hotel employees' work behaviors: Moderating effects of working-from-home. International Journal of Hospitality Management, 98, 1-10. https://doi.org/10.1016/j.ijhm.2021.103020

De Klerk, J. J., Joubert, M., \& Mosca, H. F. (2021). Is working from home the new workplace panacea? Lessons from the COVID-19 pandemic for the future world of work. SA Journal of Industrial Psychology/SA Tydskrif virBedryfsielkunde, 47(0), 1-14. https://doi.org/10.4102/sajip.v47i0.1883

Eatough, E. M., Chang, C., Miloslavic, S. A., \& Johnson, R. E. (2011). Relationships of role stressors with organizational citizenship behavior: A meta-analysis. Journal of Applied Psychology, 96(3), 619-632. https://doi.org/10.1037/a0021887

Fabiyani, N. N., Sudiro, A., Moko, W., \& Soelton, M. (2021). Conceptualizing the role of work engagement: A case study of the hotel sector in Surabaya during the COVID-19. Journal of Asian Finance, Economics and Business, 8(5), 485-494. https://doi.org/10.13106/jafeb.2021.vol8.no5.0485

Fuchs, H. U., Corni, F., Pahl, A. (2021). Embodied simulations of forces of nature and the role of energy in physical systems. Education Sciences, 11(759), 1-32. https://doi.org/10.3390/educsci11120759

Galanti, T., Guidetti, G., Mazzei, E., Zappala, S., \& Toscano, F. (2021). Work from home during the COVID-19 outbreak: The impact on employees' remote work productivity, engagement, and stress. Journal of Occupational and Environmental Medicine, 63(7) 426-432.

Gagnier, R. (1993). On the insatiability of human wants: Economic and aesthetic man. Victorian Studies, 36(2), 125-153.

Garavan, T., McCarthy, A., Lai, Y., Murphy, K., Sheehan, M., \& Carbery, R. (2021). Training and organizational performance: A meta-analysis of temporal, institutional and organizational context moderators. Human Resource Management Journal, 31, 93-119. https://doi.org/10.1111/1748-8583.12284

Giurge, L. M., \& Bohns, V. K. (2020, April 3). 3 Tips to avoid WFH burnout. Harvard Business Review. https://hbr.org/2020/04/3-tips-to-avoid-wfh-burnout

Harter, J. K., Schmidt, F. L., \& Hayes, T. L. (2002). Business-unit-level relationship between employee satisfaction, employee engagement, and business outcomes: A meta-analysis. Journal of Applied Psychology, 87(2), 268-279. https://doi.org/10.1037//0021-9010.87.2.268

Harunavamwe, M., Nel, P., \& Van Zyl, E. (2020). The influence of self-leadership strategies, psychological resources, and job embeddedness on work engagement in the banking industry. South African Journal of Psychology, 50(4) 507-519. https://doi.org/10.1177/0081246320922465

Hu, J., He, W., \& Zhou, K. (2020). The mind, the heart, and the leader in times of crisis: How and when COVID-19-triggered mortality salience relates to state anxiety, job engagement, and prosocial behavior. Journal of Applied Psychology, 105(11), 1218-1233. https://doi.org/10.1037/ap10000620

International Labor Organization. (2021). ILO monitor: COVID-19 and the world of work (7th ed.). Updated 
estimates and analysis. $\quad$ Retrieved https://www.ilo.org/global/topics/coronavirus/impacts-and-responses/WCMS_767028/lang--en/index.htm

Kalmus, I. P. (1993). The forces of nature. Interdisciplinary Science Reviews, 18(4), 343-349.

Kalvin, J. (2021). Attaining high employee engagement proves challenging due to covid's impact - HR research institute releases results of 2021 survey. PR Newswire, 1-3.

Karani, A., Deshpande, R., Mall, M., \& Jayswal, M. (2021). Testing the link between psychological contract, innovative behavior and multidimensional wellbeing during the COVID-19 pandemic. International Journal of Sociology and Social Policy, 1-17. https://doi.org/10.1108/IJSSP-02-2021-0032

Karani, A., \& Mehta, S. A. (2021). "I am OK when you are with me" - Understanding the wellbeing and innovative behavior in the digitized workspace. International Journal of Sociology and Social Policy, 1-20. https://doi.org/10.1108/IJSSP-05-2021-0127

Klatt, M., Bawa, R., Gabram, O., Westrick, A., \& Blake, A. (2021). Synchronous mindfulness in motion line: Strong results, strong attendance at a critical time for health care professionals (HCPS) in the COVID era. Frontiers in Psychology, 12, 1-9. https://doi.org/10.3389/fpsyg.2021.725810

Kotera, Y., Mayer, C. H., \& Vanderheiden, E. (2021). Cross-cultural comparison of mental health between German and South African employees: Shame, self-compassion, work engagement, and work motivation. Frontiers in Psychology, 12, 1-15. https://doi.org/10.3389/fpsyg.2021.627851

Lee, Y., Tao, W., Queenie, J., \& Sun, R. (2021). Enhancing employees' knowledge sharing through diversity-oriented leadership and strategic internal communication during the COVID-19 outbreak. Journal of Knowledge Management, 25(6), 1526-1549. https://doi.org/10.1108/JKM-06-2020-0483

Liu, D., Chen, Y., \& Li, N. (2021). Tackling the negative impact of COVID-19 on work engagement and taking charge: A multi-study investigation of frontline health workers. Journal of Applied Psychology, 106(2), 185-198. https://doi.org/10.1037/ap10000866

Macey, W. H., \& Schneider, B. (2008). The meaning of employee engagement. Industrial and Organizational Psychology, 1, 3-30.

Mehta, P. (2021). Work from home-Work engagement amid COVID-19 lockdown and employee happiness. Journal of Public Affairs, 1-12. https://doi.org/10.1002/pa.2709

Miglioretti, M., Gragnano, A., Margheritti, S., \& Picco, E. (2021). Not all telework is valuable. Journal of Work and Organizational Psychology, 37(1), 11-19. https://doi.org/10.5093/jwop2021a6

Mikołajczyk, K. (2021). Changes in the approach to employee development in organizations as a result of the COVID-19 pandemic. European Journal of Training and Development, 1-19. https://doi.org/10.1108/EJTD-12-2020-0171

Obrad, C. (2020). Constraints and consequences of online teaching. Sustainability, 12, 6982, 1-23. https://doi.org/doi:10.3390/su12176982

Oksa, R., Kaakinen, M., Savela, N., Hakanen, J. J., \& Oksanen, A. (2021). Professional social media usage and work engagement among professionals in Finland before and during the COVID-19 pandemic: Four-wave follow-up study. Journal of Medical Internet Research, 23(6), 1-10.

Palumbo, R. (2020). Let me go to the office! An investigation into the side effects of working from home on work-life balance. International Journal of Public Sector Management, 33(6/7), 771-790. https://doi.org/10.1108/IJPSM-06-2020-0150

Patil, M. R., \& Rana, P. (2021). Employee engagement in times of crisis. Bioscience Biotechnology Research Communication, 14(05), 01-06.

Restubog, S. L., Ocampo, A. C., \& Wang, L. (2020). Taking control amidst the chaos: Emotion regulation during the COVID-19 pandemic. Journal of Vocational Behavior, 1-6. https://doi.org/10.1016/j.jvb.2020.103440

Robinson, B. (2020, June 19). Is working remote a blessing or burden? Weighing the pros and cons. Forbes. Retrieved

from https://www.forbes.com/sites/bryanrobinson/2020/06/19/is-working-remote-a-blessing-or-burden-weighingthe-pros-and-cons/

Routley, N. (2020). 6 charts that show what employers and employees really think about remote working. World Economic

Forum.

Retrieved

from 
https://www.weforum.org/agenda/2020/06/coronavirus-covid19-remote-working-office-employees-employe rs

Rožman, M., Peša, A., Rajko, M., \& Štrukelj, T. (2021). Building organizational sustainability during the COVID-19 pandemic with an inspiring work environment. Sustainability, 13, 1-22. https://doi.org/10.3390/su132111747

Schade, H. M., Digutsch, J., Kleinsorge, T., \& Fan, Y. (2021). Having to work from home: basic needs, wellbeing, and motivation. International Journal of Environmental Research and Public Health, 18, 1-18. https://doi.org/10.3390/ijerph18105149

Schmaus, D., \& Wimmer, R. (2013). Government policy and postsecondary education in Alberta: A 'field theory' analysis. Alberta Journal of Educational Research, 59(1), 92-107.

Shamsi, M., Iakovleva, T., Olsen, E., \& Bagozzi, R. P. (2021). Employees' work-related wellbeing during COVID-19 pandemic: An integrated perspective of technology acceptance model and JD-R theory. International Journal of Environmental Research and Public Health, 18, 1-22. https://doi.org/10.3390/ijerph182211888

Shepherd, D. A., \& Suddaby, R. (2017). Theory building: A review and integration. Journal of Management, 43(1), 59-86. https://doi.org/10.1177/0149206316647102

Shuck, B., \& Wollard, K. (2010). Employee engagement and HRD: A seminal review of the foundations. Human Resource Development Review, 9(1), 89-110. https://doi.org/10.1177/1534484309353560

Skurak, H. H., Malinen, S., Näswall, K., \& Kuntz, J. C. (2021). Employee wellbeing: The role of psychological detachment on the relationship between engagement and work-life conflict. Economic and Industrial Democracy, 42(1) 116-141. https://doi,org/10.1177/0143831X17750473

Song, L., Wang, Y., Li, Z., Yang, Y., \& Li, H. (2020). Mental health and work attitudes among people resuming work during the COVID-19 pandemic: A cross-sectional study in China. International Journal of Environmental Research and Public Health, 17, 1-15. https://doi.org/10.3390/ijerph17145059

Tao, W., Lee, Y., Sun, R., Li, J., \& He, M. (2021). Enhancing employee engagement via leaders' motivational language in times of crisis: Perspectives from the COVID-19 outbreak. Public Relations Review, 48, 1-15. https://doi.org/10.1016/j.pubrev.2021.102133

Torraco, R. J. (2005). Writing integrative literature reviews: Guidelines and examples. Human Resource Development Review, 4(3), 356-367. https://doi.org/10.1177/1534484305278283

Torraco, R. J. (2016). Writing integrative reviews of the literature: Methods and purposes. International Journal of Adult Vocational Education and Technology, 7(3), 62-70. https://doi.org/10.4018/IJAVET.2016070106

Torraco, R. J., \& Lundgren, H. (2020). What HRD Is doing-What HRD should be doing: The case for transforming HRD. Human Resource Development Review, 19(1), 39-65. https://doi.org/10.1177/1534484319877058

Varshney, D. (2021). How about the psychological pandemic? Perceptions of COVID-19 and work-life of private sector employees-A qualitative study. Psychology Study, 66(3), 337-346. https://doi.org/10.1007/s12646-021-00605-y

Xanthopoulou, D., Baker, A. B., Demerouti, E., \& Schaufeli, W. B. (2009). Reciprocal relationships between job resources, personal resources, and work engagement. Journal of Vocational Behavior, 74, 235-244. https://doi.org/10.1016/j.jvb.2008.11.003

Zheng, M. X., Masters-Waage, T. C., Yao, J., Lu, Y., Tan, N., \& Narayanan, J. (2020). Stay mindful and carry on: Mindfulness neutralizes COVID-19 stressors on work engagement via sleep duration. Frontiers in Psychology, 11, 1-13. https://doi.org/10.3389/fpsyg.2020.610156

\section{Copyrights}

Copyright for this article is retained by the author(s), with first publication rights granted to the journal.

This is an open-access article distributed under the terms and conditions of the Creative Commons Attribution license (http://creativecommons.org/licenses/by/4.0/). 